\title{
Perspectives of Adolescents, Parents, Service Providers and Teachers on Mobile Phone Ownership, Access and use For SRH Information Among Adolescents
}

\section{Monica A Magadi \\ University of Hull \\ Lesley Smith \\ University of Hull \\ Bev Orton \\ University of Hull \\ Mark Hayter \\ University of Hull \\ Margaret Kaseje}

Beverlyn Marion Ochieng ( $\square$ beverly_ochieng@yahoo.com )

Great Lakes University of Kisumu

Tropical Institute of Community Health and Development

Charles Ouma Wafula

Tropical Institute of Community Health and Development

\section{Peninah Ocholla}

Tropical Institute of Community Health and Development

\section{Salmon Owii}

Tropical Institute of Community Health and Development

\section{Franklin Onukwugha}

University of Hull

\section{Dan Clement Kaseje}

Tropical Institute of Community Health and Development

\section{Research article}

Keywords: Adolescents, Sexual and Reproductive Health, Mobile health, service access, service utilization, Health Education.

Posted Date: June 29th, 2021

DOl: https://doi.org/10.21203/rs.3.rs-663929/v1

License: (c) (i) This work is licensed under a Creative Commons Attribution 4.0 International License. Read Full License 


\section{Abstract}

Introduction: Mobile health (mHealth) programmes offer opportunities to improve sexual and reproductive health $(\mathrm{SRH})$ for adolescents by providing information. Researchers define mHealth as a "medical and public health practice supported by mobile devices". mHealth is increasingly used to deliver health interventions including adolescent SRH. However, knowledge gaps remain regarding the utilization and effectiveness of these programmes. This study reports findings of a qualitative study carried out in Homabay County, Kenya.

Purpose: We aimed to establish if mHealth would facilitate access of SRH information by adolescents, and whether adolescents would participate in SRH-related content delivered on mobile phones, based on their experiences and existing constraints.

Methods: This was a qualitative exploratory study seeking to gain an understanding of the experiences of adolescents concerning their mobile phone ownership, access and use. The study population included adolescents, parents, teachers and health care workers and community health volunteers (CHVs). Data were collected through 25 Focus Group Discussions (FGDs) and 19 key informant interviews (KIIs). The FGDs consisted of five groups each for girls, boys, fathers, mothers and CHVs. We purposively selected five primary school heads, five secondary school heads and nine health facilities in-charges for KIls. Data were analyzed through thematic and qualitative content analysis.

Results: Mobile phone use was frequent among adolescents accessing phones from parents and friends. The most popular use of mobile phones was short messaging service (SMS) with girls and boys citing chatting, SMS and watching movies. Service providers emphasized accessing health knowledge. Teachers emphasized accessing SRH information. All respondent categories highlighting ease of access and potential reach to large numbers of adolescents and hence an effective and efficient approach. Respondents lauded the potential of mobile phones to promote learning of useful SRH information among adolescents to influence their behavior formation, modification and or change by learning about diseases and receiving advice. Mobile phones overcame barriers experienced by adolescents when seeking sensitive SRH information and services such as stigma, discrimination, and lack of privacy and confidentiality.

Conclusion: Mobile phones can provide safe, accurate, cost-effective, and timely SRH information and services tailored to the needs of adolescents to influence their behavior

\section{Background}

Young people under the age of 25 years account for $43 \%$ of the world's seven billion people. Adolescence, defined as 10-19 years, is a crucial period in life during which young people undergo extensive biological, psychological, and sociological changes. It is a crucial time for lifelong health development and improving health behaviours at this stage of life contributes to the health of future generations as described by Hindin and Fatusi[1] and Dick and Ferguson [2]. Sexual and reproductive health (SRH) is an important component of life during adolescence and can affect many aspects of life during and after this period. Empirical evidence over the past 20 years has highlighted the challenges faced by adolescents in accessing SRH information and services particularly regarding contraception to avoid unplanned pregnancy. Existing evidence shows that early sexual debut is the key contributing factor for adolescent pregnancy and childbearing. SRH knowledge and information is important for promoting contraception related behaviour change in adolescents [3]. 
Kenya, like other countries in the developing world has poor adolescent sexual and reproductive health (ASRH) indicators. Adolescent pregnancy, estimated at about $18 \%$ of the adolescent girls in Kenya, is a major problem, compounded by an unmet demand for family planning services [4]. About 13000 girls drop out of school every year in Kenya due to early unintended pregnancy [4]. Homabay County has among the highest prevalence of teenage pregnancy in the country, the prevalence being nearly 4-5 times higher than the national average [4]. Adolescents aged $10-19$ years contribute to $28 \%$ of all new HIV infections in Homabay County [4].

Hence the Kenya National health sector strategic plan 2015-2020 has recognized ASRH as a priority within the essential health care package.

The use of mobile and wireless technologies (mHealth) has the potential to transform health service delivery globally and support the achievement of the UN Sustainable Development Goals (SDGs) in low and middle-income countries (LMICs). According to the International Telecommunication Union almost the entire world population (97 per cent) lives within reach of a mobile cellular signal [5]. Mobile health (mHealth) interventions use mobile phones for patient monitoring devices, personal digital assistants (PDAs), or other wireless devices to provide health information to change health behaviors and outcomes [6]. The content for a mHealth app can be standardized, tailored, and have interactive features, with potential higher impact than face-to-face interventions due to a wide reach at a lower cost. mHealth interventions are ideally suited for adolescents owing to their widespread use of smart phones and internet.

Mobile health (mHealth) programmes offer opportunities to improve sexual and reproductive health for adolescents by providing information and support, but further research is required to inform the development of tailored approaches for adolescents [7, 8, 9, 10, 11]. Feroz and colleagues [10, 12] define mHealth as a "medical and public health practice supported by mobile devices". Overall, mHealth interventions for adolescents have demonstrated increased SRH knowledge and behavior [13,14]; and increased the use of reproductive health interventions or services $[13,14,15,16]$. Despite their promise, there is still a dearth of knowledge about efficacy, and a need for further research into effective content creation and implementation approaches. Kay, Santos and Takane [17] highlight knowledge gaps in mHealth for adolescents in LMICs. A systematic review by L'Engle and colleagues noted that only three out of the 35 articles included in the review were from LMICs [18]. Strassberg and colleagues [19] add that published research from Sub-Sahara Africa is particularly sparse.

While mHealth programmes are increasingly used to provide health information and deliver interventions including adolescent $\mathrm{SRH}$, knowledge gaps remain regarding the utilization and effectiveness of these programmes across socio demographic profiles. In this paper we report findings of a qualitative study carried out in Homabay County to explore perspectives of adolescents, parents, service providers and teachers on mobile phone ownership, access and use for SRH information by adolescents in an effort to understand if mobile phones have the potential for integration into adolescent SRH services. We aimed to establish if mHealth could facilitate access of SRH information, especially by adolescents at risk of teenage pregnancy, and whether adolescents might even participate in or engage with SRH-related content delivered on mobile phones. In order to better understand the potential to deliver mobile phone based SRH to adolescents in resource limited settings with poor ASRH indicators, we addressed the following questions:

1. What are the experiences of adolescents in the use of mobile phones in Homabay County?

2. What are the perceived disadvantages and constraints in mobile phone use by adolescents?

3. How can perceived constraints in adolescents' use of mobile phones be addressed? 


\section{Methods}

\subsection{Study design and methods of data collection}

This was a qualitative exploratory study among adolescents seeking to gain an understanding of the experiences of adolescents concerning their mobile phone ownership, access and use. The notion is that the approach allows us to explore the issue from the perspective of adolescents, looking at the lived experience of the individuals [20]. The sociological approach explains how people live their lives in their context. Within this inquiry our objective was to assess the phenomenon of phone ownership, access and use among adolescents. According to Cilesiz [21] phenomenology can be used as a framework for understanding the experiences as well as developing a research agenda which considers individual's experiences with technology [21]. The interview guides were specifically developed for this research study (Annex 3 and 4).

The study population included adolescents, parents, teachers and health care workers from hospitals, health centres and community health worker in Homabay County. Qualitative data were collected through Focus Group Discussions (FGDs) and key informant interviews (KIIs). We purposively selected in all the sub-counties a total of 25 FGDs consisting of community health volunteers (CHVs), (5), fathers (5), mothers (5), adolescent girls (5) and boys (5). Each of the FGDs had minimum of 8 participants and maximum of 12 (Annex 1).

For key informant interviews (KIIs), we purposively selected 5 primary school heads, 5 secondary school heads and 9 health facilities in-charges.

A summary of KII participants is presented in Annex 2.

Senior members of the research team conducted qualitative interviews. For adolescent minors aged under the age of 18 years, parents provided informed consent by signing a consent form on behalf of the students. All students above the age of 18 provided written assent to participate. To ensure high quality of data, the Principal Investigator (PI) and study coordinators supervised data collection, and reviewed issues arising in the field at daily evening meetings to ensure that each study team followed and complied with the protocol.

The study protocols and consent forms were reviewed and approved by relevant institutional ethics review boards in the UK (University of Hull) and Kenya (Masinde Muliro University Ethical Review Board).

The national research clearance certificate and permit was obtained from National Commission for Science, Technology and Innovation (NACOSTI)

\subsection{Data Analysis}

For all qualitative data, dual English-local language speakers on the study team transcribed and translated the audio-recorded interviews into English. Transcribed interviews were analyzed through thematic and qualitative content analysis [22] using the NVivo qualitative analysis software package version 12. Thematic analysis was based on a descriptive phenomenological tradition, thematizing meaning using a descriptive approach, with focus on lived experiences [23]. The following stages were followed in the analysis of the qualitative data. We developed qualitative analysis and coding frameworks based on the themes presented in the specific research questions and categories of respondents in the protocol. We coded the narratives (transcribed interviews) and uploaded them in the NVivo software packages by the different categories of respondents. The coding process identified similarities, outliers, and recurring themes in interviews. We created charts and analysis matrixes using headings from the thematic framework. Headings and emerging sub themes were added as suggested by the data during analysis. 


\section{Results}

\subsection{Phone use by adolescents and preferred platforms}

The majority of FGD and KII respondents of all categories identified common use among adolescents to be communication by phone calls and text messaging. Other uses mentioned were: playing games, searching for information, reading, entertainment (watching videos, movies, listening to music) and, taking photos and videos (see Table 1). There was no gender difference in preferred platforms. The most cited uses by girls and boys were chatting, SMS, listening to music and watching movies. Service providers emphasized the aspect of searching for information and health knowledge: "Sexual reproductive health issues today adolescents don't struggle, they just look for it is in their hands" Explained a reproductive health officer (KII H13). 
Table 1

Use of, preferred platforms and benefits of mobile phones by respondent category

\begin{tabular}{|c|c|c|c|c|c|c|c|c|}
\hline Themes & Main findings & Boys & Girls & Mothers & Fathers & CHV & Providers & Teachers \\
\hline \multirow[t]{9}{*}{ Use } & Calls & + & + & + & + & + & + & + \\
\hline & SMS & + & + & + & + & + & & + \\
\hline & Games & + & + & & + & & & + \\
\hline & Reading & + & & & & & & \\
\hline & watching videos, movies & + & + & + & + & + & & \\
\hline & listening to radio, music & + & + & + & + & & & + \\
\hline & Photos/video & + & + & & & + & + & + \\
\hline & Info search, fashion, porn & + & + & + & + & & + & \\
\hline & Getting news & & + & & & & & \\
\hline \multirow[t]{11}{*}{ Platforms } & WhatsApp & + & +++ & + & & + & + & + \\
\hline & Google & + & ++ & + & + & & + & + \\
\hline & Facebook & ++ & +++ & + & + & + & + & + \\
\hline & Twitter & + & + & & & & + & + \\
\hline & Instagram & + & ++ & & & & + & + \\
\hline & YouTube, & ++ & + & & & & + & + \\
\hline & Manager, & + & & & & & & \\
\hline & betting sites & + & & & + & & & \\
\hline & music platforms. & + & & & & & & \\
\hline & Internet & & + & & & & & \\
\hline & Snapchat & & & + & & & & \\
\hline \multirow[t]{8}{*}{ Benefits } & Fast information reach & + & + & + & + & + & + & ++ \\
\hline & Learn SRH information & + & ++ & +++ & & + & + & ++++ \\
\hline & Effective, efficient & & + & & + & & + & ++ \\
\hline & Privacy & & & & & & +++ & ++ \\
\hline & Clinic appointments & & & & & & ++ & \\
\hline & Education platforms & & + & & + & & + & +++ \\
\hline & Relevance & & + & & & & +++ & \\
\hline & Bridge generation age gap & & & & + & & & \\
\hline
\end{tabular}

+ indicates frequency of responses mentioned by the specific group of respondents. 


\begin{tabular}{|c|c|c|c|c|c|c|c|c|}
\hline Themes & Main findings & Boys & Girls & Mothers & Fathers & CHV & Providers & Teachers \\
\hline & Exchange ideas & & & & & + & & +++ \\
\hline & Financial transactions & & & + & & & & \\
\hline & Appealing & & & + & & + & & \\
\hline & Access & & & & & & & ++ \\
\hline & Correct misconceptions & & & & & & & ++ \\
\hline
\end{tabular}


Table 2

Challenges with mobile phones by respondent category

\begin{tabular}{|c|c|c|c|c|c|c|c|c|}
\hline Themes/subthemes & Main findings & Boys & Girls & Mothers & Fathers & CHV & Providers & Teachers \\
\hline \multirow[t]{2}{*}{ Cost } & $\begin{array}{l}\text { Buy phone, } \\
\text { bundles, } \\
\text { betting, } \\
\text { demanding }\end{array}$ & ++++ & + & +++ & +++ & ++++ & ++ & ++ \\
\hline & $\begin{array}{l}\text { Leads to } \\
\text { stealing }\end{array}$ & ++ & & ++ & & + & & +++ \\
\hline $\begin{array}{l}\text { Impact on school } \\
\text { performance: }\end{array}$ & $\begin{array}{l}\text { Through } \\
\text { addiction, }\end{array}$ & ++ & ++ & +++ & & + & + & + \\
\hline \multirow[t]{3}{*}{ Misuse: } & $\begin{array}{l}\text { Porn, } \\
\text { misinformation } \\
\text { may promote } \\
\text { loose morals, } \\
\text { early sex, }\end{array}$ & +++ & +++ & ++++ & ++++ & ++++ & +++ & ++++ \\
\hline & $\begin{array}{l}\text { Betting, bad } \\
\text { company }\end{array}$ & +++ & & ++++ & ++++ & & & ++++ \\
\hline & $\begin{array}{l}\text { Cheating } \\
\text { exams }\end{array}$ & & & & & & & ++++ \\
\hline \multirow[t]{3}{*}{ Poor logistics: } & Connectivity & + & + & & & & & ++ \\
\hline & Charging & + & + & & ++ & + & + & \\
\hline & Analogue & + & & & + & & & + \\
\hline $\begin{array}{l}\text { No Privacy, } \\
\text { confidentiality }\end{array}$ & $\begin{array}{l}\text { Sharing e.g. } \\
\text { with parents? }\end{array}$ & + & & & & + & & \\
\hline Limited Access: & $\begin{array}{l}\text { Accessing } \\
\text { smart phone. } \\
\text { Not allowed in } \\
\text { school, phone } \\
\text { loss }\end{array}$ & + & + & + & + & + & ++ & ++ \\
\hline Parental control: & $\begin{array}{l}\text { Difficult, } \\
\text { limited access }\end{array}$ & & + & + & & + & + & \\
\hline Relevance & $\begin{array}{l}\text { For age, } \\
\text { language, style }\end{array}$ & + & ++ & & & + & & + \\
\hline Stigma & $\begin{array}{l}\text { Being judged } \\
\text { negatively by } \\
\text { peers, parents, } \\
\text { society }\end{array}$ & + & ++ & & & + & ++ & \\
\hline Knowhow: & $\begin{array}{l}\text { Info access, } \\
\text { misinterpret }\end{array}$ & & + & + & & + & + & + \\
\hline External influence & & & & ++ & & & ++ & ++ \\
\hline
\end{tabular}

Almost all respondents from all categories mentioned WhatsApp, Google and Facebook as preferred platforms by adolescents. Adolescents, health service providers and teachers also mentioned Twitter, You Tube and Instagram. Face book and WhatsApp were the most popular platforms mentioned by both the boys and girls in addition to 
service providers and teachers who also mentioned the same platforms as the adolescents, including You Tube, Instagram, and Twitter. However, parents and CHVs did not see these platforms to be popular among adolescents. Other platforms mentioned especially by adolescent boys included manager, betting sites, music platforms, and snap chat, (Table 1).

\subsection{Benefits of mobile phone use by adolescents}

Among all participants, teachers perceived the most benefit of mobile phone use by adolescents, identifying several advantages, including learning SRH information. Commonly cited benefits fell under four categories: ease of information access; learning enhancement; effective/efficient means of education; and bridging intergenerational gap. Girls cited a number of benefits which included fast information search, learning of SRH information, which was much emphasized, efficiency and effectiveness, relevance and education platforms. On the other hand, adolescent boys mentioned only two benefits, fast information search and learning of SRH information.

\subsubsection{Ease of information access to reach large numbers}

All participants expressed the view that information provided through phones reaches faster in creation of awareness and to a wider intended audience, "Through mobile phone messaging you can reach many people" commented a male in school aged 14-18 (FGD B04).

This view was supported strongly by the parents, CHVs, health service providers, and even teachers. Mothers emphasized that the use of phones is good because adolescents are able to search for SRH information. "It is efficient, effective and will reach a large number of adolescents especially in educating them on SRH information". - Mother respondent ( FGD M19).

Boys added the element of calling for help especially in emergencies or in a crisis, and ease of transferring money which was supported by the mothers, while girls added entertainment, and making friends. "I also support the need to bring the information through the phones because most young people like using the phones seriously" remarked a mother respondent (FGD M16). A health service provider added "They can get the information about sexually transmitted infection (STI), and also the HIV which is good for them because they can get the right information through the mobile phone". - Explained a Medical Superintendent (KII H12)

Teachers supported this view, adding that adolescents using mobile phones would get first-hand information, read it at their own pace, analyze and understand it. They also thought that mobile phones would be a great tool for campaigns. Adolescents would share information among themselves towards the desired reproductive health behavior formation. A teacher gave an example. "We can form WhatsApp groups or post information on Facebook, and through these they access and get enlightened" - Head Teacher (KII T02). Teachers explained that adolescents were inquisitive and wanted to know more information, hence mobiles phones would be a great way to meet their $\mathrm{SRH}$ information needs, being an easy means of communication, and faster in relaying information." Smart phones access internet faster and brings information in a clearer way even pictorials and videos", stressed a teacher (KII T04).

\subsubsection{Enhances, promotes learning of critical information:}

Respondents expressed the importance of mobile phones in enhancing learning useful information which included $\mathrm{SRH}$ information among adolescents towards behavior change and behavior formation such as the need to abstain from sex and the importance of using a condom if one had to have sex, to avoid HIV and STI infections. Majority of 
both boys and girls mentioned that through the phone they were able to learn about diseases, health education and receive advice "It can be good because it will help to reduce the number of HIV infections" explained a male in school aged 14-18 (FGD B05)

"It can give information about new emerging disease so that young boys can know about it early enough". Added another male in school aged 14-18 (FGD B05). Other boys added:

"It can be good because it can reduce the number of abortion". Said a male in school aged 14-18 (FGD B04). "It is good because sometimes when someone is sick they can access the information about the illness from the phone" said a male in school aged 14-18 (FGD B04). "For me I think it can help more so when you went somewhere and you have been attacked you can call other people to come a help you", said a male in school aged 9-13 (FGD B01).

Girls added that they would learn of remedies of such problems as what to do especially when having cramps during periods by taking hot water. The majority were of the view that mobile phone sources of SRH information were good because they provided a learning platform and gave advice, so they considered them trustworthy. All respondents agreed that most of the SRH information was appropriate, educative and current "We get SRH educative materials on phone which will help me change my bad behavior" (explained a female in-school adolescent aged 14-18 (FGD G08).

Parents (both mothers and fathers) and health service providers added that young people could learn how to prevent themselves from sexually transmitted diseases and existing family planning methods and their advantages and disadvantages. The majority of mothers supported the idea that young people could get useful information through phones. They felt that young people could inquire and learn more about SRH information for example girls on issues to do with monthly periods, how to avoid pregnancy and what to do in case one got pregnant. They added that SRH information via mobile phone would improve the lives of young people by increasing their knowledge, and that mobile phone messaging of SRH information was a useful learning platform for adolescents. This view was supported by CHVs, adding that mobile phones help in searching for useful information. However, fathers did not mention learning of SRH information as a benefit for adolescents' use of mobile phones.

Fathers and service providers added that phones could aid learning and research for adolescents.

"phones can be used to teach and educate young people in so many ways number one the phone can help them in researching on SRH latest information and it can be of help in educating them when they have questions regarding an issue, they can also use it to research about exams and revision and you they can get past revision papers" Explained a father (FGD F13). "Like searching for information on abortion once a lady's pregnant, they will really want to know how abortion is done. How is it being managed and then they get some few drugs there and then they look at how they can get those drugs. See that is the right information they will get we can get that information" Said a Nurse service provider (KII H11).

The aspect of searching for information, learning, research were among the advantages strongly expressed by teachers who mentioned that phones enabled students to do research for their home works and conduct academic group discussions through the phone through chats, to learn about growth, changes and understanding themselves even as they grow and so they felt it was a good tool which they were already using. Phones could address their curiosity to know about the changes they were experiencing in their bodies and desire to learn about new information. In their view searching for advice or particular SRH information were the driving forces. "If they are exposed to this information then I want to believe that they will be better off. If you tell them that they are going to

Page $10 / 29$ 
get pregnant when they have sex, then they now think that if I don't want to get pregnant they are given an option of going to put that thing family planning", explained a senior teacher (KII T01). Respondents concluded that if adolescents used phones for intended purposes then phones were good. "But if the phones are used to give useful information then they just use it. "Yeah - But you know with them they don't go into those deep one. If they can use this phone in a very positive manner, an educate manner they can Google, they can you know they can open the phone read. You get information from the phone that can empower them" explained a teacher (KII T03).

\subsubsection{Effective and efficient:}

Mothers mentioned the effectiveness of using videos through mobile phones to educate young people because it was appealing to their age and they got exposed to many different things.

"It will be beneficial to them as they will be able to know and understand the effects of engaging in unhealthy relationships at a tender age, unlike if it is left for the parents to talk to them of which most of them will not take it seriously. So it will be better for them to decide on their own what exactly they want to do with their lives" explained a mother (FGD M18). This view was supported by service providers and teachers. They mentioned both positive and negative effects. The general feeling was that mobile phone was a powerful learning tool if adolescents and parents were sensitized and educated on the importance of SRH messages delivered through phones.

Teachers stressed that phones were a powerful learning tool especially on SRH where it requires privacy. "Mobile phones can be used as a great tool for campaign. Where one, they can share information among themselves for the desired behavior regarding reproductive health, and hence enhance the campaign. So in that regard, it would be of great help. It can enable us reach a good number within a short period. For example we can form WhatsApp groups or post information on Facebook they access and get enlightened"Explained a school principal (KII T10).

They added that phones provided relevance and appropriateness to the SRH messages.

The privacy aspect was also highlighted by health service providers expressing the importance of mobile phones in accessing sensitive information at individual level. Providers added its usefulness in making hospital appointments. They viewed mobile phone information received as relevant and educative particularly if the language was simple and acceptable, a view supported by $\mathrm{CHVs}$ who also emphasized the need to use simple language.

\subsubsection{Helps to bridge intergenerational gap:}

Fathers added that mobile phones SRH messaging would bridge the information gap between parents and adolescents "I think it is useful to use phones because as a parent, you might have such information to share with your child but there is shyness which will not allow you to share with her or him some information. Therefore, phones can make him/ her receive all the information without any shyness" explained a father (FGD F11). CHVs and teachers supported the view stressing the importance of exchange of ideas, dialogue and advice. Thus, adolescents were able to access phones from parents and friends and relatives particularly smart phones. "Those who then don't have, will definitely when they find someone with a phone, they will be there. They want to learn. And you know once the youth...somebody has learnt something they will tell their colleagues (KII T09). A teacher explained for those who don't have they usually access from parent's phones. "Some parents give permission to use their phones to his or her child to use some give them I don't deny that," said a deputy principal teacher (KII T06).

Teachers added that phones could be used to correct misconceptions, suggesting that packaging the information properly would help to clarify some of the misconceptions. "The positive effect is that if we filter the information 
and the correct information given to the youth, I believe they will learn the right things. And they will also try to do the right things and avoid doing the negative things that they get through I call it "dirty media", explained a head teacher (KII T02) (See Table 3).

Table 3

Solutions by respondent category

\begin{tabular}{|c|c|c|c|c|c|c|c|c|}
\hline Theme/subthemes & Key findings & Boys & Girls & Mothers & Fathers & CHV & Providers & Teachers \\
\hline $\begin{array}{l}\text { Sensitization and } \\
\text { awareness: }\end{array}$ & $\begin{array}{l}\text { Parents, } \\
\text { teachers, } \\
\text { religious leaders }\end{array}$ & + & + & + & + & + & + & ++ \\
\hline Credible source: & $\begin{array}{l}\text { Trustworthy, } \\
\text { informed, } \\
\text { Resource } \\
\text { persons }\end{array}$ & ++ & ++ & & & & & ++ \\
\hline \multirow[t]{2}{*}{ Regulation } & $\begin{array}{l}\text { Controlled, } \\
\text { approved } \\
\text { content for age, } \\
\text { use }\end{array}$ & ++ & +++ & & & + & +++ & ++ \\
\hline & Guidelines & & & & + & & + & \\
\hline $\begin{array}{l}\text { Inclusive } \\
\text { participation }\end{array}$ & $\begin{array}{l}\text { Adolescents, } \\
\text { parents, } \\
\text { teachers, } \\
\text { religious leaders }\end{array}$ & ++ & ++ & ++ & + & & + & + \\
\hline Create a platform: & $\begin{array}{l}\text { SRH app, } \\
\text { dedicated, free, } \\
\text { WhatsApp }\end{array}$ & ++++ & +++ & ++ & + & + & +++ & ++ \\
\hline Form health clubs: & $\begin{array}{l}\text { SRH centres, } \\
\text { learning rms }\end{array}$ & ++ & ++ & & & & + & ++++ \\
\hline Use other channels & $\begin{array}{l}\text { Schools, } \\
\text { churches, } \\
\text { concerts, camps, } \\
\text { TV, radio, video, } \\
\text { use champs }\end{array}$ & ++ & & & & ++ & ++ & +++ \\
\hline Training: & $\begin{array}{l}\text { Train on phone } \\
\text { use }\end{array}$ & & + & + & + & + & + & +++ \\
\hline Guidance, counsel & How to use & + & & & & & & ++ \\
\hline $\begin{array}{l}\text { Make affordable, } \\
\text { provide support: }\end{array}$ & $\begin{array}{l}\text { Free phones, } \\
\text { bundles, access }\end{array}$ & ++ & + & ++ & + & + & + & \\
\hline $\begin{array}{l}\text { Enhanced } \\
\text { connectivity }\end{array}$ & & & & & & + & + & \\
\hline Create a hotline: & Customer service & & + & & & + & + & \\
\hline Use alt energy & Solar & & & & + & & & \\
\hline
\end{tabular}


While acknowledging the benefits of mobile phone use by adolescents as outlined above, the participants recognized a number of challenges and constraints ranging from cost, poor logistics and access issues to potential misuse, impact on school performance and limited technical knowhow.

3.3.1 Cost: All respondents recognized cost as a challenge, which could lead to stealing (mentioned by different groups of participants, except girls, fathers and service providers). Respondents found it expensive to buy bundles or even cost of repairing a spoilt phone. This view was supported strongly by parents, teachers and service providers. They explained that phones were expensive, and required money to access the information. Adolescent boys, more than adolescent girls, strongly expressed the high cost of buying phones and bundles as a barrier to accessing SRH information through mobile phones. In their opinion boys expressed that many adolescents would miss out on the SRH information through mobile phones, because they had to buy bundles and that it was expensive to buy a phone meaning majority of adolescents would not own one and so they would not be able to access the SRH information sent through the phone. "Using a phone needs money and we cannot afford to get the money so that's a challenge" explained a male in school aged 9-13 (FGD B02). Another male respondent in school aged 9-13 (FGD B01) added "Accessing phone for adolescents like us is not easy because we are still in school and we cannot have enough money to afford buying a phone so it might force some to steal or we can take from another person".

Parents supported the sentiments expressed by boys. Fathers emphasized the high cost of purchasing the phone and data bundles, given the high poverty levels. "Phones are expensive and majority of families are poor, the cost of buying bundles to access information is very high" explained a father. Mothers added their voice on the cost challenge. "Young people have become more demanding for money to buy phone and bundles, which are expensive" expressed a mother (FGD M20).

The CHVs agreed that poverty was a major challenge limiting the use the phones by adolescents due to cost of purchasing phones and bundles. "The platform needs the use of money. For young people to get money, becomes a challenge because they are still in school. That can bring problems where they can even steal from their parents. Even if they don't steal from the parents, they might look for the money from friends who they think will give them money, so that they can get money to subscribe if the platforms are not free" explained a CHV (FGD C22).

Service providers, supported by teachers emphasized financial challenges involved in buying bundles

"Not all our adolescents can afford smart phones, and bundles to access internet". Said a Reproductive Health Officer (KII H14). "Like you know now phones are very expensive and a child cannot own one mostly the high school kids and the primary children they cannot own one. So it may lead them to taking your money to buy their own", added a Clinical Officer (KII H18).

Teachers added "They can corn someone so that they get their own. The boys can do fishing, you will find them in the lake looking for money to buy just a phone not even to pay school fees or buy uniform and most of them have these phones. They get their money from the lake and that is a disadvantage towards the parents and the teachers". - School Teacher (KII T07). Teachers further added that "Because of the desire to own a phone they may be tempted to collude with blackmailers to demand for ransom money. Phones encouraged stealing for example when they demand money for betting or for buying bundles when they are not given, they are tempted to steal'.- Deputy Principal (KII T06). 
The cost challenge was not expressed strongly by girls who seemed to be more concerned about the cost of purchasing bundles, rather than phones. However, CHVs explained that the issue of high cost of purchasing the phone could lead to young girls involving themselves in sexual relationships in order to get money to buy one. "Peer pressure to own phones at times leads to stealing to own one. The desire to own a mobile phone was overwhelming driven by peer influence to own a phone", said a CHV (FGD C25).

\subsubsection{Limited access}

\section{Phone ownership}

The majority of adolescents, both boys and girls, said that access was a general challenge because of lack of ownership of a mobile phone. They said that they had to rely on their parent's phone, relatives or rich friends who owned one. In addition, most of the times they were in school especially those in boarding schools where phones were not allowed, viewed phone access as a challenge." Then we also know that not everyone has a phone, some do not have. So those who do not have cannot get this information, so even as we go to the churches, from the church you can find some that are serious with the information who knows it can help them. So this method helps both" explained a male in school aged 14-18 (FGD B04).

The challenge of limited access was supported by all respondent categories. Mothers added low literacy levels and high poverty levels in the rural areas." Not all adolescents will receive the information because not all of them have phones, School going children are not allowed to use phones therefore could hinder him/her from receiving the information properly" said a father respondent (FGD F15) .

Therefore, using mobile phone for SRH messaging will lead to discrimination against those who do not have leading to unhealthy competition and even stealing. Teachers added that most adolescents did not own phones but even those who had mobile phones would have limited access if they were not smart phones (analogue). "we have the policy and they know it and when they come we search them thoroughly and we don't tolerate that, So the only time they would have access to phones is during the holidays" Explained a deputy school principal (KII T10).

\section{Poor logistics}

Adolescents, boys and girls mentioned lack of strong network services in the rural area. "The message might not reach the intended recipient since it requires a literate person who can read, sometimes our parents don't have phones that can Google so it will mean that you look for other ways to access a phone" mentioned a female in school aged 9-13 (FGD G07). Another issue mentioned was lack of electricity to charge the phones, at the right time. These logistical issues were supported by the fathers, CHVs, providers and teachers. "Some people do not even have electricity or solar to charge the phone, at all times" said a father respondent (FGD F14). Teachers also mentioned loosing the phone.

\section{Parental restrictions}

The adolescents, both boys and girls, were quick to mention that permission to use the phone was not easily granted by parents, especially when it was an expensive smart phone, while a few had different views, saying that permission could be granted depending on how adolescents used the phone.

"Parents don't agree because I might spoil it or block the phone so they deny me". Said a in school male aged 9-13 (FGD B02). Access of phones was generally a challenge expressed by both boys and girls.

They all agreed that not all parents agreed to share their phones with them. 
Making statements like "They cannot allow because we can mishandle the phones"; said a male in school aged 913 (FGD B01). "They cannot agree because they fear that I would block the phone or spoil it" added a male in school aged 14-18 (FGD B05). "It may not be easy because most of the parents are against the use of mobile phones more so for students they see that they get distracted with their studies" explained a female in school aged 14-18 (FGD G09).

In general, mothers were the most hesitant responded category, concerning the idea of young people accessing the mobile phone freely. According to them the disadvantages outweighed the advantages.

"Most parents may not understand the need of giving their phones to the children and so may not take it seriously, parents have not been adequately informed about the importance of SRH information so they will not give adolescents phones" explained a mother respondent (FGD M17).

A CHV raised the issue that phone sharing could bring conflict between the parents and their children, a view supported by service providers.

\subsubsection{Impact on school performance}

The impact on school performance was mentioned by all respondent categories except the fathers. Boys mentioned the challenge of balancing school time and phone usage. "Maybe one is school going, so they cannot get that time to be with the mobile phone; maybe there is a restriction that they should always be reading". Said female in school aged 9-13 (FGD G06). "You find that most adolescent have diverted their mind to betting than concentrating in school they took a lot of time knowing everything through WhatsApp than concentrating in their book' said a male in school aged 14-18 (FGD B05). Girls added that phone addiction would leads to poor performance in school, lack of concentration in class, and lack of time to use phone, "When we are addicted to phone it can lead to us dropping out of school and even failing in the exams, once you are addicted you will not understand anything being taught in class because you will keep thinking about it all time" added a female in school aged 14-18 (FGD G10).

Mothers added to the concern of disadvantages of phone use such as distractions in studies, and wasting their time betting instead of studying adding that phones were not allowed in schools.

"Children between the ages of 10-19 years, or even 5-19 years are supposed to be in school and therefore should concentrate on their books, issues to do with the phone should be no"said a mother (FGD M16) respondent adding that mobile phone messaging posed a big challenge in interfering with adolescents' concentration in studies. These views were supported by CHVs, providers and teachers.

\subsubsection{Misuse}

Misuse of mobile phones by adolescents was the most commonly cited challenge, highlighted by all groups of participants. Adolescents mentioned that they could misuse phones when given opportunity by viewing bad photos such as pornography that can ruin their lives by spreading false information. Other issues raised were that watching of pornographic movies could spread misleading information promoting immoral behavior, early boy girl relationships, practice of early sex and early marriages.

"Sometime he sends you pornographic videos and he would wish that you do the same and this may result into pregnancies. Watching pornographic videos makes you horny" explained a female in school aged 14-18 (FGD G07). "It can encourage someone also to engage in bad things like drug abuse or immorality especially with information from face book" added another female in school aged 14-18 (FGD G09). Girls said that use of mobile 
phone was not good because it provided misleading and wrong information on matters like abortion especially from Facebook which was the most popular platform mentioned and used.

The issue of phone misuse in watching pornography was mentioned by all respondent categories. Mothers were eager to mention the negative effects of the use of mobile phones by young people. "Looking at very nasty things and encourages early sexual relationships, cheating and immoral behavior" Mother respondent (FGD M18). The boys also mentioned that mobile phones would encourage bad company. This was supported by the mothers explaining that they facilitated connections with wrong people (strangers), connecting with wrong friends through WhatsApp chats. Mothers expressed their anger on how phones were an instrument of destruction. "The teachings they get are just negative", Mother (FGD M20). "They get the opportunity to ... at that time they are busy seducing one another through the phone, and it is very easy for them to start such behaviors when the phone is easily accessible in the house". - Mother (FGD M17). "Mmhh, no I do not think these children have received any teaching from the mobile phone, there is nothing good they get from the phones" expressed another mother respondent relating to girls adolescents - Mother (FGD M16).

Mothers lamented that access to phone would increase the chances of them talking to their boyfriends/ girlfriends because they would be having the phone most of the time. Fathers expressed the need for young people to be sensitized on the need to use their mobile phones resourcefully and not to misuse the opportunity by watching pornography and betting. They supported views expressed by adolescents such as phones can be used to spread rumors and false information, promotion of early sexual relations among young people and, encouraged lying. They felt that the potential to misuse and abuse the mobile phone discouraged parents from giving adolescents the phone. "As a parent I don't expect a child of that age bracket to have a phone. I view it in a different way and wonder where the child has gotten the phone from. I will therefore feel that she/he might get spoilt. Therefore I don't want them to use phones" explained a father (FGD F15).

The health service providers and teachers supported the parents' sentiments.

"This can lead to the rise in adolescent relationships. It could be...because if you hear of lack of money...the adolescent can engage in some activities to get money so as to buy their own phone they must now have a phone because they will have heard of the advantages of owning one. That is one of the negative effects that can come about. This can be a very big problem" expressed a CHV (FGD C21). "Phones expose them to pornography, early sexual relationships and influence from social media, and peer influence, by content presented to the adolescents, and language used", said a clinical officer (KII H16). "The temptation to visit such sites is overwhelming. It is such an aid to accessing pornographic material... because of the embarrassment and restriction at the Cyber Cafés, the mobile phones have presented an opportunity for one on one interaction to visit the site through their mobile... mobile phone. Most of them have... a good number of them now have" expressed a head teacher (KII T02). "I may not allow my children to use at that tender age. Yeah. I don't advocate for it" expressed a teacher (KII T09).

Teachers expressed much concerns that although there were positive and negative effects of mobile phones, the general feeling was that the mobile phone was a powerful learning tool if adolescents and parents are sensitized and educated on the importance of SRH messages delivered through phones, but expressed much caution and gave an example: "But they should not have it ruin their lives. This is where you'll find someone has annoyed her/him and that's where she/he will abuse her"; - Teacher (KII T08). "The boys feel that they are now grownups like you and to some extent if you are not just strict then you may not control them"-Deputy Principal (KII T10). "Like the young girls we have here, a man would lure them and give them a simple phone because this is a big favor now you see you must tow the line of this person so those who do not have might do all the plans to get a phone";- Teacher

Page 16/29 
(KII T07). "once they have seen those pornographic films they want also to practice them and the effect of practicing is that they get pregnant they get sick, and like in school now they are destructed they are not focused they can also leave school because they are pregnant early marriage just go out of school, can't take it anymore, this man is out there wanting me yes and he can provide these things that I want so they say let school be yeah let it be" expressed Senior teacher (KII T01). Teachers added that phones encouraged cheating in exams, and betting addiction instead of focusing on beneficial and educative materials.

\subsubsection{Relevance of information, privacy and stigma:}

Majority of the adolescent respondents, boys and girls, noted the fact that some of the information could be irrelevant for their age, and that messages needed to be tailored to suit the adolescents. The other concern raised was use of simple language and ensuring that the content was captivating to the adolescents. "I think some may be relevant and some may not be relevant like the ways of preventing STIS, HIV I think those are relevant and others like watching pornographic movies I think those are not relevant, you get that the pornographic movies you watch you end up with occupied mind with movie you watch but they are of not good to you, you see you are a pupil or student you are watching pornographic movies I don't see the use of it, so some may be relevant and other may not" Explained a female in school aged 14-18 (FGD G08). This was supported by a teacher who said "They might receive information that is not relevant for them at their age" Head teacher (KII T02)

The issue of privacy was raised by boys and fathers. Boys believed that sharing with parents was not something easy. "It does not have privacy someone can access your communication easily and it can cause disagreement between you and your parent" said male in school aged 9-13 (FGD B02)

Fathers concurred that there was no privacy when a child demands to access parents' phone.

The majority of respondents, boys and girls felt that owning a phone and accessing the SRH messages could lead to them being negatively judged by parents, peers and society. Girls explained that parents often made very negative discouraging remarks like "Those who have and access the messages through the phone are spoilt and stupid while the young people will make you feel like the odd one out"; Father (FGD F12). "You will be like a stupid one because this one is busy with the phone, so you will feel that you are not among them and not part and parcel of them" - Father (FGD F15). They were supported by CHVs and service providers: "I think it can lead to stigma in the beginning, since anything new that comes must be stigmatized by people. So as it starts they will be stigmatized, but as it goes on they will continue learning, and more people will be receptive" explained a CHV (FGD C24). Providers agreed that stigma was from fellow young people and community members explaining that "You hear comments like somebody's child nowadays is full of himself/herself I don't even know how they acquired the phone and they even sleep hungry You know that is stigmatizing irrespective of how you obtained the phone"- Registered Nurse respondent (KII H20). "Fear of the unknown, they don't have any experience, some are just being careful" said a Head teacher (KII T05).

\subsubsection{Lack of technical knowhow}

Girls, mothers, $\mathrm{CHVs}$, providers and teachers expressed concern about the ability of adolescents to use the phone to access SRH information, "Not all young people know how to operate the phone" said a mother respondent (FGD M16). CHVs added the issue of low literacy levels as a challenge, and use of technical scientific RH language can be hard to understand. This was supported by service providers and teachers. Saying, there was a need for the health workers to explain further. Teachers added that most parents did not take reproductive health seriously, because of taboo. Parents did not discuss SRH issues with their children, and as a result the children were left on their own to experiment. "And that's why you find that most of the youth are getting themselves into problems. They 
misinterpret the SRH information "maybe what you intended for them they take it the other way round so you may not hit the significance of that ... the information may not hit the point in that they may misuse that information otherwise they can change it around and use it as it suites them" explained a Deputy principal (KII T06).

Mothers opposed the idea of SRH mobile phone messaging saying "I don't see any benefits for bringing the teaching through the mobile phone", and "I think they should just be brought together and taught because 10 year olds will not be able to learn those things from the phone effectively, so having them together is the only way out to help them better so group discussion will be the most appropriate method as compared to teachings brought through the mobile phone", and "the teaching should not be brought through the mobile phones, let experts be brought from different fields and teach them like someone to talk to them on issues of family planning, be discussion can even be designed that girls and boys are taught separately, that could be better" asserted several mothers (FGDs M17,M19, M20).

\subsection{Addressing challenges and constraints}

Participants suggested a variety of ways in which the identified challenges and constraints could be addressed. These included: availing resources to address logistic/infrastructure and cost/access challenges; ensuring credibility and age appropriateness of information; use of innovative channels/platforms for ASRH education; improving community knowledge/awareness and attitudes (especially parents) through training and sensitization; and improving adolescent's technical knowhow.

\subsubsection{Inclusive participation and awareness to improve access and use:}

Both adolescent boys and girls advocated for sensitization and awareness raising among parents on the SRH mobile phone messaging so that they could give them permission to access the phone. They suggested that there should be continuous teaching on SRH education. All respondent categories supported the adolescents on this view. There was need for sensitization on the importance of the SRH messages to both the adolescents and their parents. A teacher explained the need saying

"We need to campaign and I think we've not adequately addressed the issue of sensitization. Sensitization of parents and teachers"-senior teacher (KII T01)

Adolescent boys and girls advocated for the involvement of core stakeholders such as adolescents, parents, teachers and service providers for the program to be acceptable across the society. Involving the parent and explaining to them the importance of the SRH messages sent through the phone to allow adolescents access the information, and in the development of appropriate SRH messages. They also suggested that the government should create awareness through advertisements on advantages and disadvantages of the SRH messaging model. They added the need to create awareness in schools and churches about the messaging program and to involve all teachers, parents and religious leaders.

Mothers emphasized that they should also be involved, saying: "Bringing that information through the phone is just okay; but let the information be brought through the parents' phones so that the parents can read and tell them what they are supposed to do, but if it's the children by themselves then no".--Mother respondent (FGD M17). Fathers, providers and teachers added the involvement of religious and opinion leaders. Teachers recommended that the content could be shared with service providers like Safaricom, Airtel... the mobile...service providers to 
disseminate it in partnership to enhance penetration of the messages. "How I wish that the community, that is the parents and even the elders and even the churches come up with this forum, where the youth are advised, on reproductive health and the importance of it in their lives. Most of the time the youth are just discovering on their own through mobile phones or even through some...the television. Yeah. So nobody is there to guide them" exclaimed a teacher (KII T03).

\subsubsection{Relevance and age-appropriateness of information:}

Both adolescent boys and girls stressed the importance of trustworthy sources of information, provided by people and organizations that are knowledgeable and with a good reputation, relaying correct SRH information. Teachers suggested inviting resource persons to talk to them. "May be if we have visitors some new people who can come and talk to the adolescents in schools, I think it might help because there is a stage when they will need these phones for example when they go to colleges after secondary they will need these phones. There are a lot that they will learn from the phones but in primary there is totally nothing"-Said a Teacher respondent (KII T08). They mentioned the need for sources to be reliable, like ministry of education and messages to be channeled through schools, using champions to complement education of adolescents. They also suggested the use of a reputable media houses to advertise the importance of SRH mobile phone messaging. "The danger is which source of information, if at all we could have a way in which the service providers could filter some information so that the youth cannot get those ones that are distracting to them, then it will be okay. Unfortunately, I believe there is no way they can filter that. Maybe through television, they can do that through the Communications Authority of Kenya, but through the mobile phone, you know, it's very difficult. How I wish they could come with a way of filtering this information that can assist us with the youth, then it can go on" Explained a teacher (KII T09).

Both adolescent girls and boys, raised the issue of age appropriateness of SRH messages sent through the phone. "I think that the service providers, they should have a way of controlling the messages that get to the adolescent and limit the bad messages from being posted, appropriate and age specific SRH messages for the adolescents" Said a male in school aged 14-18 (FGD B05). The Girls mentioned the issue of false information on SRH and recommended the need to regulate by an approved organization that can create an app with specialized SRH information for adolescents and educate the adolescents on how to use the phone and the app. The general view by both girls and boys was that a SRH source should be approved by the government and should limit SRH messages to reproductive health messages only.

These views of adolescents were supported by parents, service providers and teachers.

Fathers added the need for guidelines to be developed on how to access the SRH information and restrictions put in place to restrict abuse. CHVs recommended that schools and the ministry of health should be the sources to disseminate the information because they are trusted and known by everyone.

Service providers added that messages should also be region specific like urban and rural regions. They proposed the formation of a technical committee for developing the information to address the issue of fear of the unknown to the parents regarding adolescent SRH information. Teachers added "I think we can tailor information that is towards that direction then phones can be of great help because you know our... the students of these ages are always on the phones they are always on the phone if they have such information then it would be easy for them to just read. We can tailor make the SRHR messages to the adolescent sexual health and package it" - Senior Teacher (KII T01). 
Girls added the need for adolescents to be truthful and straight forward when putting their request to their parents to use a phone. "If we want to use phone to get information let us just be straight forward and go straight to get the information on health and return the phone so that next time when we ask for it then they will be giving us freely not asking themselves what we are going to do with the phone" Expressed a female in school aged 14-18 (FGD G09). "There are some parents who don't like their children to have phones so you can sit your parent down and explain to them the benefits you can get while using the phone and if they agree they would just give you chance to use it" expressed a female in school aged 9-13 (FGD G06).

\subsubsection{Develop a special platform and innovative channels/platforms for ASRH education}

All respondents recommended the development of a special SRH app that could be downloaded and installed on a mobile phone, for free access by adolescents. Mothers welcomed the idea of an SRH app emphasizing on creating a special program through the phone for SRH education. "I think it can help because once the teachings are programmed in the mobile phones, then these people can just be taken for some workshop and be taught on the effective use they betaught on the effects of engaging in certain types of relationship at that age since that age of 10-19 they are school going and having a group discussion on some issues will greatly help them during that time they should also call issues the way they should; calling a spade a spade" - explained a mother (FGD M16) stressing that messaging should be packaged in a more attractive way. This was supported by fathers, CHVs, and providers. Providers stressed the need for creativity in developing SRH messages.

Other ways mentioned were to create links that can be shared through cloud messages that can be shared probably with trusted and known entities like Safaricom Citizen TV, NTV, Airtel, partner in collaboration with the ministry of health and education, create a centre for learning in detail the SRH messages sent. Teachers explained further, "yes we have phones that are programmed then we even allow the parents to buy those phones just like we have text books that are recommended for students we can recommend such kind of phones that already are programmed. The engineers should add some apps that are containing health information facts. Involve I.C.T into it to make it innovative and the media people. It should be an interactive platform in which they are able to ask questions and they are answered"- Deputy Principal (KII T06 ). "School can have a program, you log in and you had earlier said that the information needs to be packaged to suit different ages once you have the package then you can talk to ministry of education or the ministry of education can initiate it or is it something that can be initiated maybe at the county level, or in schools, at whatever level but it must be interaction between ... it must be coordinated through the ministry of health and ministry of education Tailor made phones for the SRH messaging information, developed purely for age appropriate SRH educative materials". Explained a teacher (KII T03).

Boys, girls, mothers, service providers and teachers strongly recommended introduction of health clubs, where the SRH messages can be communicated to adolescents, free of charge. Providers added the creation of theatre groups, as well as a register of adolescents in the area for teaching and follow up, Teachers added the creation of dedicated SRH learning spaces/rooms/time. Phone access should be within a given time. They also highlighted the need to introduce SRH programmes in schools. Participants suggested the need of information be disseminated through media channels like radios or TV which have a wider audience, easily accessed and reaches wider geographical areas. "For me I think the information can be relayed through the television since no one is hindered from watching the television" explained a male in school aged 9-13 (FGD B03). "I think the idea for making the information reach the young people through the mobile phones could be reverted and the information could be 
passed through the TV or even the radio for it to reach many young people, because phone access can be a challenge to many young people so it could be relayed through the TV or radio" explained a mother (FGD M18).

Respondents also mentioned dissemination through music concerts, use of theatre arts, videos, films, holiday camps and distribution of educational materials and to teach SRH in churches. Health service providers added the use of champions to advocate the SRH messaging programme, by organizing campaigns and holiday camps to teach about SRH issues. A teacher added "After the campaign, we register and map them. As we register them, then they network and have a call running. We know that so and so is a champion of formation of champions... for reproductive health... sexual and reproductive health...so and so. So they become our ambassadors wherever they go". - Head Teacher (KII T02)

\subsubsection{Training adolescents on how to use, and supporting them}

Training of young people in groups to learn about the SRH information relayed through the phone was mentioned by majority of the respondents who stressed the need to train young people on mobile phone usage, teaching adolescents on how to use the phone. Boys added the elements of guidance and counseling. They were supported by mothers who added the need for free access to information, education on how to operate the phone. Fathers added seminars for adolescents on the importance of SRH mobile phone education. CHVs mentioned the need to use simple understandable language in addition to training. While providers added that not only adolescents needed training but also teachers and service providers in order for them to effectively influence utilization. "Since phone use for SRH information is new, creation of awareness is very key" remarked a Reproductive Health officer service provider (KII H15).

Teachers added several statements on preparing adolescents to use phones effectively for $S R H$

"In schools we are trying because we have the health club, which talks to them about their health. We've even talked to them, we advise them at the assemblies, especially when they're closing school, that when they're going out, they're out of school, where we cannot monitor them, that they should be careful of their lives because any decision they make will have consequences". Senior Teacher (KII T01). Teachers stressed the need to guide and counsel adolescents on proper use of mobile phones for SRH educational purposes. They explained the need to talk to the adolescents on avoiding bad sites.

"We can control the usage of these phones at home we should also do some close supervision on what they are accessing. Guide and counsel them, give them the positive side and the negative side of using because everything has both sides". - Head Teacher (KII T02). "We should advice them not to use them to see what they should not see at their ages. To do what they should not do at that age" a head teacher explained. They stressed the need for close monitoring through establishing counseling centers where the information can be accessed, learnt and shared by adolescents under supervision" Teacher (KII T07). "You don't just let them loose". Explained a Deputy Principal teacher (KII T10).

\subsubsection{Addressing the problem of cost}

Adolescents were of the view that if SRH through mobile phone was to be introduced as a school programme then free phones would need to be provided, and information be freely accessed. "For everybody to access SRH information the information should be free of charge" suggested a female in school aged 9-13 (FGD G06). Boys added the alternative of subsidized, cheap phones, or shared phones at SRH service centers. 
"Implementing agency should buy mobile phones for young people so that they can get the information more easily" suggested a mother (FGD M19) or "provide financial support for adolescents coming from poor households" suggested a father. Regarding bundles girls said it was good to request parents to buy them bundles or borrow from someone like a friend or family member to access the internet or the messages sent" suggested a female in school aged 14-18 (FGD G08). They could also request parents for their phones to access messages on WhatsApp.

These views were supported by CHVs and service providers. Providers suggested that the government should speed up the installation of fiber optic so that young people can access the SRH information, install free public WIFI in central areas where young people can access the internet, and that service providers should ensure strong internet connectivity. Respondents suggested alternative power sources such as charging the phone using solar panels instead of electricity. Providers suggested the creation of a hotline dedicated to the adolescents for SRH help.

\section{Discussion}

\subsection{Phone use by adolescents: acceptability and benefits}

Findings show that mobile phone use was frequent among adolescents, but many relied on parents and friends to access the phone. The most popular use of mobile phones by adolescents was short messaging service (SMS). This finding has been reported by other researchers. A survey conducted in 24 developing nations on mobile phone use revealed that the majority $78 \%$ of cell phone users used SMS [24, 25], and another study by Hampshire [26] reported similar results: $77 \%$ of adolescents aged 14-18 used SMS, making it the most common method of communication among adolescents. SMS remains the most frequently used mobile phone communication format among youth in Sub-Saharan Africa (SSA) as reported by several studies [27, 28]. Identifying the most preferred platform is critical to inform the designs of SRH mHealth interventions.

Respondents reported that mobile phones provided ease of information access to reach large numbers of adolescents, noting that information provided through phones would reach faster to wider coverage of intended audiences in creation of awareness and enhancing critical knowledge. They felt that it was an effective and efficient way to communicate sexual and reproductive health (SRH) information since adolescents were responsive and enthusiastic to use new innovative technologies and could use mobile phones to access SRH information since it addresses critical barriers to receiving SRH information and services as observed by Perry [29]. Diverse mHealth solutions have been used to connect adolescents to SRH information and services [30].

Respondents lauded the potential of mobile phones to promote learning of useful SRH information among adolescents to influence their behavior formation, modification and or change such as the need to abstain from sex and the importance of using condoms, to avoid pregnancy and sexually transmitted infections (STIs). Adolescents in this study mentioned that through mobile phones they were able to learn about diseases, healthy lifestyle and receive advice. Studies have shown that it is an appropriate approach to provide acceptable, safe, cost-effective, and accurate SRH information and services [31,32,33]TThe findings were also consistent with those of a study carried out by Kelly and others [34], indicating that mHealth programmes can increase health knowledge and that such programmes tend to be well-received by youth. $[10,7]$.

It was noted that phones can address adolescent's curiosity to know because of the changes they are experiencing in their bodies and the desire to learn about new information. They would thus access accurate information and correct misconceptions, [34]. It was noted that mobile phones addressed several barriers to SRH information and 
services for adolescents such as the need for privacy and confidentiality in accessing sensitive information. Adolescents highlighted many barriers experienced by them when seeking SRH information and services such as stigma and discrimination by health care workers. Previous evidence has demonstrated that mobile phones can provide safe, accurate, cost-effective, and timely SRH information and services tailored to adolescents [31]. Other studies have proven that mobile phones offer privacy and convenience [35], while highlighting the importance of including interactive features and feedback in the design of mHealth programmes for adolescents. Our study also indicated that use of games is popular among adolescents and could be incorporated into mHealth programme designs.

\subsection{Challenges and constraints to SRH information through mobile phones}

The challenges/concerns to adolescent SRH information through mobile phones cited by respondents included: restricted access; cost; impact on school performance; and lack of technical knowhow. Adolescents reported parental restriction as a barrier to phone use to access information, while they also noted the fact that some of the information could be irrelevant for their age, and that SRH messages needed to be tailored to suit the adolescents, using simple language and easy to understand content. Respondents highlighted the fact that some adolescents could misuse phones, when given opportunity, to view pornographic materials with misleading information, and others could use it for betting. Many of these challenges have been reported by other researchers [36, 27]. Yet a report by UNESCO urges caution pointing out that anti-mobile phone sentiments and the banning of the use of mobile phones in school premises were among the most significant barriers to learning using mobile phones [37].

Adolescents and other respondents expressed the high cost of buying phones and bundles as a barrier to accessing $\mathrm{SRH}$ information through mobile phones. Further respondents stressed that the strong desire to own and manage a phone could lead to young girls involving themselves in sexual relationships in order to get money to buy one, or boys stealing from their parents or going into child labour. Related studies have identified the difficulties adolescents may experience accessing cell phones due to cost or poor socio-economic status [38, 39] while other opined that mHealth programmes do not reach vulnerable adolescent populations [40, 8].

Impact on school performance was mentioned by all respondent categories noting that phone addiction would lead to poor performance in school, lack of concentration in class, and lack of time for schoolwork, all of which are well documented in literature [41], suggesting that addictive phone use can lead to less academic engagement among adolescents [42]. In addition, researchers have reported disturbed sleep patterns by frequent cheap night phone calls $[43,44]$, and bullying, harassment and exploitation, particularly of the female adolescents given the minimal on-line child protection [45] and widespread access to pornographic materials through mobile phones [46, 47].

Respondents expressed concern about the inability of adolescents to use the phone to access SRH information, due to low literacy levels, worsened by technical scientific SRH language. They also suggested that adolescents should be trained and supported in phone use, and to accompany phone messaging with guidance and counseling, findings that may be unique to the local context of this study. This would require dedicated space and time for accessing SRH information. In a study in Kenya and South Africa UNICEF observed that inadequate mobile technology skills among parents increased the vulnerability of adolescents to exploitation and harassment as well as misuse of the phone [45].

\subsection{Addressing constraints}




\subsubsection{Develop adolescent specific, well regulated app}

The participants suggested various ways of addressing the identified challenges in the local context: developing a well-regulated adolescent specific app; targeting the most disadvantages groups in program design; and ensuring technical support to adolescents. Adolescents stressed the need for high quality, regulated age-appropriate SRH information, from trustworthy sources like the ministry of educations, and/or health. Respondents suggested the development of a special SRH application that could be downloaded and installed on a mobile phone, for free access by adolescents. The platform should include innovative features such as interaction and feedback in the design as described by Chen, Wellman and cook [40,48]. Livingstone and Bulger [49] emphasize the need to teach adolescents the importance of informed choice in virtual environments. Additionally, respondents stressed the need for inclusive participation of key stakeholders such as adolescents, parents, teachers and service providers during the development and dissemination of the SRH messages for the program to be acceptable across the society, not commonly identified by researchers.

Efforts should be made to target disadvantaged adolescents. Amy in her study [50] reports that age and education are the most important predictors of mobile phone ownership among adolescents. Our quantitative findings in this study showed that phone ownership among the adolescents was quite low, less than $20 \%$. Thus, it has also been described by other researchers such as Porter[51] who noted that while mobile phone ownership and usage has greatly expanded among young people in many LMIC settings, adolescents from disadvantaged groups generally tend to have low rates of ownership, or may only have limited access to a shared household phone [52, 53]. Suggested solutions to make access to phones more equitable included introducing them through school programs providing phones and information accessed freely at SRH service centres. Since the availability of cell phone, along with increasing capability for the devices to carry and transfer data suggest that they will reach more people than computers and the Internet in coming years, across socioeconomic backgrounds [34].

Respondents suggested that adolescents should be trained and supported by accompanying phone messaging with guidance and counselling. This would require dedicated space and time for accessing SRH information. Findings by UNICEF [54] suggests the need to train and educate parents, and teachers on mobile phone use in addition to training adolescents themselves [54]. UNESCO advocates for promoting responsible mobile phone use rather than banning [55]. This view is supported by our findings as well as research evidence from other studies [56, 57 and 58].

\section{Conclusions}

There is great potential of mobile phones to promote learning of useful SRH information among adolescents to influence their behavior formation, modification and or change such as the need to abstain from sex and the importance of using condoms, to avoid pregnancy and sexually transmitted infections (STIs). Both boys and girls agreed that they were able to learn about diseases, healthy lifestyle and receive advice. Evidence from this study indicates that adolescents face many barriers when accessing SRH information and services. This heightens the need for a mobile phone supported SRH interventions as mHealth enabled programmes since they can provide safe, confidential accurate and timely SRH information and services to adolescent.

\section{List Of Abbreviations}

ASRH- Adolescent Sexual Reproductive Health 
LMIC- Low Middle Income Countries

MHealth - Mobile Health

NACOSTI - National Commission for Science, Technology and Innovation

SRH- Sexual and reproductive health SRH

STI - Sexually Transmitted Infections

UNESCO- United Nation Education Organization

UNICEF - United Nations Children's Fund.

\section{Declarations}

\section{Ethics approval and consent to participate}

All participants provided written consent to participate in the study. For adolescent minors aged under the age of 18 years, parents provided informed consent by signing a consent form on their behalf. All students above the age of 18 provided written assent to participate. The study protocols and consent forms were reviewed and approved by relevant institutional ethics review boards in the UK (University of Hull) and Kenya (Masinde Muliro University Ethical Review Board). The national research clearance certificate and permit was obtained from National Commission for Science, Technology and Innovation (NACOSTI)

Consent for publication: All authors read and approved the final manuscript.

\section{Availability of data and materials}

The datasets used and/or analyzed during the current study are available from the corresponding author on request.

Competing interests: The authors declare no competing interests.

Funding: The study reported in this paper was funded by QR-GCRF (Research England) pump-priming fund (EAL012) from the University of Hull, UK.

\section{Authors' contributions}

BMO: Developed the analysis framework, spearheaded data analysis, and synthesized the contributions of the other authors into the first draft of the manuscript.She further engaged actively in the revision of the manuscript in response to critiques from co-authors and took the lead in editing the manuscript based on internal peer reviewers' comments.

MM: participated in conceptualizing and designing the study, tool development, and data analysis, She reviewed and contributed to data analysis, edited the first manuscript draft and made suggestions and inputs towards the final draft. 
LS: participated in designing of the study, tool development, and data analysis; edited the first manuscript draft and made suggestions and inputs towards the final draft.

BO: participated in designing of the study, tool development, and data analysis; edited the first manuscript draft and made suggestions and inputs towards the final draft.

MK: participated in designing of the study, tool development, and contributed to the drafting of the discussion section.

COW; participated in designing of the study, tool development data collection and contributed to the drafting of the discussion section.

PO: participated in designing of the study, tool development, coordinated data collection and contributed to the drafting of the discussion section.

SO: participated in data collection and contributed in the drafting of the discussion section.

FO; contributed to the study design, tool development, and data analysis; edited the first manuscript draft and made suggestions and inputs towards the final draft.

DCOK Designed the study, managed the research process, supervised all aspects of the study and the team members, participated in the analysis of data, development of the analysis framework, synthesized the contributions from other authors into the manuscript.

\section{Acknowledgement}

The study reported in this paper was funded by QR-GCRF pump-priming fund (EAL012) from the University of Hull, UK. The authors take full responsibility for the work presented.

\section{Authors' details}

1. Tropical Institute of Community Health in Africa, P.O. Box 4074-40103 Kisumu

2. The University of Hull, Cottingham Road, HU6 7RX, Hull, United Kingdom.

\section{References}

1. Hindin MJ and Fatusi AO. Adolescent sexual and reproductive health in developing countries: an overview of trends and interventions. International Perspectives on Sexual and Reproductive Health, 2009; 35(2):58-62.

2. Dick B, Ferguson BJ. Health for the World's Adolescents: A Second Chance in the Second Decade. Journal of Adolescent Health. 2015;56(1):3-6 Ihttps://doi.org/10.1016/j.jadohealth.2014.10.260

3. Mmari K, Sabherwal SA. Review of risk and protective factors for adolescent sexual and reproductive health in developing countries: an update. J Adolesc Health. 2013;53:562-72.

4. Kenya National Bureau of Statistics (KNBS), and ICF Macro. Kenya Demographic and Health Survey 2014. Rockville, MD, USA: 2015. Available at http://dhsprogram.com/pubs/pdf/FR308/FR308.pdf.

5. ITU 2019. https://www.itu.int/en/ITU-D/Statistics/Documents/facts/FactsFigures2019.pdf

6. WHO 2011. https://www.who.int/goe/publications/goe_mhealth_web.pdf

Page 26/29 
7. Vahdat HL L'Engle KL, Plourde KF, Magaria L, Olawo A. There are some questions you may not ask in a clinic: providing contraception information to young people in Kenya using SMS. Int J Gynecol Obstet. 2013;123:e26.

8. 8.Mitchell KJ, Bull S, Kiwanuka J, Ybarra ML : Cell phone usage among adolescents in Uganda: acceptability for relaying health information. Health Educ Res 2011, 26(5):770-781

9. Gonsalves L, L'Engle KL, Tamrat T, Plourde KF, Mangone ER, Agarwal S. Adolescent/youth reproductive mobile access and delivery initiative for love and life outcomes (ARMADILLO) study: formative protocol for mHealth platform development and piloting. Reprod Health. 2015; 12:67. (8)

10. Akinfaderin-Agarau F, Chirtau M, Ekponimo S, Power S. Opportunities and limitations for using new media and mobile phones to expand access to sexual and reproductive health information and services for adolescent girls and young women in six Nigerian states. Africa Journal of Reproductive Health. 2012;16:219-30. (10)

11. Rokicki, S. and Fink G. Assessing the reach of effectiveness of mHealth: Evidence from reproductive health program in adolescent girls in Ghana BMC public Health 2017; 17,969. https://doi.org/10.1186/s12889-0174939-7

12. Anam Feroz, Farina Abrejo, Sumera Aziz Ali, Rozina Nuruddin and Sarah Saleem Anam Feroz Using mobile phones to improve young people's sexual and reproductive health in low- and middle-income countries: a systematic review protocol to identify barriers, facilitators and reported. Interventions. Department of Community Health Sciences, The Aga Khan University Pakistan, 2019 (http://creativecommons.org/licenses/by/4.0/).

13. Rokicki S, Cohen J, Salomon JA, Fink G. Impact of a text-messaging program on adolescent reproductive health: A cluster-randomized trial in Ghana. American Journal of Public Health. 2017; 107(2):298-305.

14. Harrington EK, Drake AL, Matemo D, Ronen K, Osoti AO, John-Stewart G, Kinuthia J,

15. Unger JA. An mHealth SMS intervention on postpartum contraceptive use among women and couples in Kenya: a randomized controlled trial. American journal of public health. 2019 Jun; 109(6):934-41.

16. L'Engle KL, Vahdat HL, Ndakidemi E, Lasway C, Zan T. Evaluating feasibility, reach and potential impact of a text message family planning information service in Tanzania. Contraception. 2013 Feb 1;87(2):251-6

17. Kay M, Santos J, Takane M. mHealth: New horizons for health through mobile technologies. World Health Organization. 2011; 64(7):66-71.

18. L'Engle KL, Mangone ER, Parcesepe AM, Agarwal S. Ippoliti NBETMPIfAS. Reprod Health ASR Pediatr. 2016;138(3) DOl:http //dx.

19. Strassberg DS, Rullo JE, Mackaronis JE. 2014. The sending and receiving of sexually explicit cell phone photos (" sexting" ) while in high school: one college student's retrospective reports. Computers in Human Behaviour 2014 41: 177- 183.

20. 20 Davis, K. The Phenomenology of Research: The Construction of Meaning in Composition Research. $A$ Journal of Composition Theory. 1995;15(1):121-29 .

21. Cilesiz, S. A phenomenological approach to experiences with technology: Current state, promise, and future directions for research. Educational Technology Research and Development.2011;59(4): 487-510.

22. Vaismoradi M, Turunen $\mathrm{H}$, Bondas T. Content analysis and thematic analysis: Implications for conducting a qualitative descriptive study. Nursing and Health Sciences 2013;15(3):398-405

23. Sundler AJ, Lindberg E, Nilsson C, Palmér L. Qualitative thematic analysis based on descriptive phenomenology. Nurs Open. 2019; 6: 733- 739.

Page 27/29 
24. Wike R, Oates R. Emerging nations embrace internet, mobile technology: cell phones nearly ubiquitous in many countries. Washington DC: Pew Research Center; 2014

25. Poushter J, Oates R. Cell phones in Africa: communication lifeline. Washington DC: pew research Centre; 2015.

26. Hampshire K, Porter G, Owusu SA, Mariwah S, Abane A, Robson E. Informal m-health: how are young people using mobile phones to bridge healthcare gaps in sub-Saharan Africa? Soc Sci Med. 2015; 142:90-9.

27. Aranda-Jan, C.B., Mohutsiwa-Dibe, N., Loukanova, S. Systematic review on what works, what does not work and why of implementation of mobile health (m-health) projects in Africa. BMC Public Health 2014; 14, 188. http://www.biomedcentral.com/1471-2458/14/188

28. Raifman JRG, Lanthorn HE, Rokicki S, Fink G. The Impact of Text Message Reminders on Adherence to Antimalarial Treatment in Northern Ghana: A Randomized Trial. PLoS ONE 2014; 9(10): e109032. doi:10.1371/journal.pone.0109032

29. Perry RC, Kayekjian KC, Braun RA, Cantu M, Sheoran B, Chung PJ. Adolescents' perspectives on the use of a text messaging service for preventive sexual health promotion. J Adolesc Health. 2012;51(3):220-5.

30. Burns $K$, Keating P, Free $C$. A systematic review of randomised control trials of sexual health interventions delivered by mobile technologies. BMC Public Health. 2016;16(1):778.

31. Biddlecom AE, Singh S, Munthali A.. Adolescents' views of and preferences for sexual and reproductive health services in Burkina Faso, Ghana, Malawi and Uganda. Africa Journal of Reproductive Health. 2007;11(3):99110.

32. Kennedy EC, Bulu S, Harris J, Humphreys D, Malverus J, Gray NJ. "Be kind to young people so they feel at home": a qualitative study of adolescents' and service providers' perceptions of youth-friendly sexual and reproductive health services in Vanuatu. BMC Health Serv Res. 2013;13(1):455.

33. Bloomfield, G.S., Vedanthan, R., Vasudevan, L., Kithei, A., Were, M., Velazquez, E.J. Mobile health for noncommunicable diseases in Sub-Saharan Africa: a systematic review of the literature and strategic framework for research. Glob. Health 2014; 10, 49.

34. Kelly Engle, E.R Mangone, A. Parcesepe: Mobile phones interventions for adolescents sexual and reproductive health A systematic Literature Review, Peadiatrics, 2016; 138(3)(2016).21.

35. Delany-Moretlwe S, Cowan FM, Busza J, Bolton-Moore C, Kelley K, Fairlie L. Providing comprehensive health services for young key populations: needs, barriers and gaps. J Int AIDS Soc. 2015;18(2S1).

36. Ippoliti NB, L'Engle K. Meet us on the phone: mobile phone programs for adolescent sexual and reproductive health in low-to-middle income countries. Reprod Health. 2017;14(1):11.

37. UNESCO. Turning on Mobile Learning in Africa and the Middle East: Illustrative Initiatives and Policy Learning. UNESCO Working Paper 2012: Paris.

38. .D. Miller and H. Horst and D. Miller, The Cell Phone: An Anthropology of Communication. Berg Publishers, Incorporated, 2006.

39. Vahdat HLMitchell KJ, Bull S,Kiwanuka J, Ybarra ML 2011. Cell phone usage among adolescents in Uganda: acceptability for relaying health information. Health Educ Res. 2011;26:770-81. (7)

40. Chen W, Wellman B. The global digital divide-within and between countries. IT Soc. 2004;1:39-45. (35)16.

41. Dong GiSeo, YujeongPark, Min KyungKim, JaekookPark: Mobile phone dependency and its impacts on adolescents' social and academic behaviors 2016, https://www.sciencedirect.com/science/journal/07475632

42. Robert W. Kubey, Michael J. Lavin, John R. Barrows, Internet Use and Collegiate Academic Performance Decrements: Early Findings, Journal of Communication, Volume 51, Issue 2, June 2001, Pages 366- 
382, https://doi.org/10.1111/j.1460-2466.2001.tb02885.x

43. Yu JJ, Kim H, Hay I. Understanding adolescents' problematic internet use from a social/cognitive and addition research framework. Computers in Human Behaviour2013; 29: 2682- 2689.

44. 44.Porter G, Hampshire K, Abane A, Robson E, Munthali A, Mashiri M, Tanle A. Moving young lives: mobility, immobility and inter-generational tensions in urban Africa. Geoforum 2010; 41: 796- 804.

45. UNICEF. From 'What's your ASLR' to 'Do you wanna go private?'UNICEF: New York, 2011

46. Valkenburg PM, Peter J. Online communication among adolescents. An integrated model of its attractions, opportunities, and risks. Journal of Adolescent Health2011; 48(2): $121-127$.

47. Vallee D, Lavoie J, Ruglis J. Around the clock: technology and adolescent sleep patterns. Unpublished paper, World Social Science Forum, Montreal, October 2013.

48. Cook PH, Heycoop C, Anuntavoraskul A, Vibulphol J. Action research exploring information communication technologies [ICT] and child protection in Thailand. Development in Practice 2012,22(4): 574- 587.

49. Livingstone S, Bulger ME. A global agenda for children's rights in the digital age: recommendations for developing UNICEF's research strategy. LSE/UNICEF Office of Research, September 2013.

50. Wesolowski, Amy, Nathan Eagle, Abdisalan M. Noor, Robert W. Snow, and Caroline O. Buckee. 2012. Heterogeneous mobile phone ownership and usage patterns in Kenya. PLoS ONE 7(4): e35319.

51. Porter G, Hampshire K, Milner J, Munthali A, Robson E, de Lannoy A. Mobile phones and education in subSaharan Africa: from youth practice to public policy. Journal of Intenational Development. 2016;28:22-39.

52. Blumenstock JE, Eagle N. Divided we call: disparities in access and use of mobile phones in Rwanda. Inf Technol Int Dev. 2012;8:1.

53. Thirumurthya Harsha \& Richard T Lesterb Thirumuthy Harsha. M-health for health behaviour change in resource-limited settings: applications to HIV care and beyond. Bulletin, World Health Organization 2012;90:390-392

54. UNICEF/Intermedia. A (Private) Public Space: Examining the Use and Impact of Digital and Social Media Among Adolescents in Kenya. UNICEF: Washington DC, July 2013.

55. UNESCO. Turning on Mobile Learning in Africa and the Middle East: Illustrative Initiatives and Policy Implications. UNESCO Working Paper 2012: Paris.

56. Vandeyar T. Practice as policy in ICT for education: Catalysing communities of practice in education in South Africa. Technology in Society2013; 35: 248

57. Burton P. Submission by the Centre for Justice and Crime Prevention [CJCP], South Africa to UN Commission on the rights of the child: day of general discussion, 'Digital media and children's rights', 12 Sept 2014.

58. Bose A, Coccaro R. 2013. Understanding African children's use of information and communication technologies: a youth -led survey to prevent sexual exploitation online. Bangkok, ECPAT International. http://www.ecpat.net/sites/default/files/ICT\%20Research\%20in\%20AFRICAp1.pdf

\section{Supplementary Files}

This is a list of supplementary files associated with this preprint. Click to download.

- Annex.docx 